\title{
Multicentric Study on Endometrial Polyps and Endometriosis: Are They True or False Friends?
}

\author{
Laura Giambanco ${ }^{*}$, Vito Iannone1, Maddalena Borriello', Giulio Sozzi², Giuseppe Scibilia ${ }^{3}$, \\ Vito Chiantera ${ }^{2}$, Paolo Scollo ${ }^{3}$
}

${ }^{1} \mathrm{Ob} \&$ Gyn Dept., S. Antonio Abate Hospital, Trapani, Italy

${ }^{2}$ Gyn Onc Dept., Civico Hospital, Palermo, Italy

${ }^{3} \mathrm{Ob} \&$ Gyn Dept., Cannizzaro Hospital, Catania, Italy

Email: *giambanco1969@gmail.com

How to cite this paper: Giambanco, L., Iannone, V., Borriello, M., Sozzi, G., Scibilia, G., Chiantera, V. and Scollo, P. (2020) Multicentric Study on Endometrial Polyps and Endometriosis: Are They True or False Friends? Open Journal of Obstetrics and Gynecology, 10, 873-879.

https://doi.org/10.4236/ojog.2020.107008

Received: May 17, 2020

Accepted: June 30, 2020

Published: July 3, 2020

Copyright $\odot 2020$ by author(s) and Scientific Research Publishing Inc. This work is licensed under the Creative Commons Attribution International License (CC BY 4.0).

http://creativecommons.org/licenses/by/4.0/

\begin{abstract}
Many authors have reported an epidemiologic relationship between endometrial polyps and endometriosis. The joining link could be an unopposed and unbalanced estrogenic milieu. The prevalence of both, endometrial polyps and endometriosis, is quite high among general population. The presence of endometrial polyps and endometriosis could affect infertile women. We performed a retrospective multicentric study, based on data collected from three Hospitals (S. Antonio Abate, Trapani, Civico-Ascoli, Palermo, and Cannizzaro, Catania). We analyzed 285 women undergoing diagnostic/office hysteroscopy. Clinical history demographic and hysteroscopic data were collected in the same sheet, containing within informed consent. On the base of our results no relationship exists between endometrial polyps and endometriosis nor cervical polyps. It's the first time that none correlation is proved for the coexistence of endometrial polyps and endometriosis. Further research is needed.
\end{abstract}

\section{Keywords}

Endometriosis, Endometrial Polyps, Infertility, Prevalence

\section{Introduction}

A research published in 1996 found out that the presence of polyps was significantly associated with the presence of pelvic or peritoneal endometriosis [1]. Since then many Authors reported a relationship between endometrial polyps and endometriosis, suggesting a common aetiological origin of unopposed estrogenic stimulation [2]-[7]. The hypothesis about unbalanced estrogenic milieu leads to endometrial polyp and endometriosis with individual risk factors is plausible [3]. Endometrial polyps (EP) are the most frequently pathological finding of the 
uterus, usually benign. Their prevalence is unknown, even if it has been reported $82 \%$ in general population and $35 \%$ in infertile women [7] [8]. By the other side, endometriosis (E) is considered as one of the most common gynecological disorders with an estimated prevalence of $2 \%-10 \%$ within general population, higher (up to 50\%) among infertile women [9]. The true prevalence rate of endometriosis is unclear, due to different clinical presentation, as pelvic pain or sterility. Furthermore aetiology is still on debate, but endometriosis is considered as an estrogen dependent disease [10]. Because of their common hyper-estrogenic pathogenesis, endometriosis and endometrial polyps could be associated with each other. Evidence suggested their estrogen mediated relationship [11] [12], but whether endometriosis patients have higher risk of developing endometrial polyps is still to demonstrate. The purpose of this study is to evaluate if does exist and can be confirmed any association between $\mathrm{E}$ and $\mathrm{EP}$.

\section{Material and Methods}

A retrospective multicentric study was conducted on the data from 285 patients. All women were recruited at Obstetrics and Gynecology Department of S. Antonio Abate Hospital, Obstetrics and Gynecology Department of Cannizzaro Hospital and Gynecologic Oncology Department of Civico Hospital between January 2019 and June 2019. All of them were referred for a suspicion of endouterine abnormalities and underwent diagnostic or office hysteroscopy. Clinical history demographic and hysteroscopic data were collected in the same sheet, containing within informed consent. Inclusion criteria were age between 30 - 50 years and GP's request of office hysteroscopy. Exclusion criteria were age under 30 and over 50 years, known malignancies. We chose lowest age 30 years because of very low prevalence of intrauterine pathology and/or endometrial polyps in younger women.

On the basis of the questionnaire and medical history the following characteristics were considered: age, Body Mass Index (BMI), parity, infertility, miscarriages, use of hormones, kind of food, site of living (urban/rural), cervical polyps.

Hysteroscopy was done immediately after menstruation (only for women not in menopause). Saline solution as distention media and $5 \mathrm{~mm}$ hysteroscope continuous flow sheath with an operative channel for grasping or biopsy forceps were used. Patient were placed in lithotomic position, the technique avoided speculum and forceps on uterine cervix.

EP diagnosis was given only after histopathological examination. Endometriosis diagnosis was made on previous histology and/or laparoscopic findings.

\section{Statistical Analysis}

Continuous variables are expressed as median and range (min-max) and dichotomous variables (present/absent or yes/no) as number and percentage. To evaluate differences in the median and frequencies between the two groups, MannWhitney $\mathrm{U}$ test test, $\chi^{2}$ test, and Fisher's exact test were used. The data were significant if $\mathrm{P}<0.05$. 


\section{Results}

This study was conducted on 285 women, aged 30 - 50 years. 10 out 285 reported endometriosis, confirmed surgically, none reported anamnestic diagnosis. Upon hysteroscopic findings 146 had EP, 139 had normal uterine cavity (Table 1). Demographic criteria were homogeneous among the groups. We divided patients in four groups (Table 2): A, (Controls, without EP nor E), B (with EP/without E), C (with EP and E), D (without EP/with E) (Table 2). Only 1.05\% had both EP and E, group C (3/285). The following data were recorded (Table 3): age, BMI, parity, abortion, previous or on-going use of hormones (estroprogestins or progestins), residence (urban or rural), feed (omnivorous, vegan or vegetarian). Furthermore we assessed whether cervical polyps were more frequent among one of patient's group. Group D counted of 7 patients, $2.45 \%$ of all the patients, $5 \%$ of women without EP. Conversely group A and group B were comprehensive of the majority of women, $46.3 \%$ and $50.2 \%$ respectively. Group C was the smallest, including only 3 women (1.05\%). We were unable to perform a comparative analysis between endometriosis stage and EP, because E diagnosis was reported by women albeit based on previous surgical findings. Our data showed no association between endometriosis and endometrial polyps. When we focused the attention on parity and abortion, we highlighted $34 \%$ of group A women and $16 \%$ of group B had given birth, respectively $10 \%$ and $23 \%$ hah almost 1 spontaneous abortion. None differences resulted among type of residence (urban or rural), nor type of feed (omnivorous, vegan or vegetarian, gluten free). Hormonal therapies didn't influence the presence of EP, E patients were more common to take hormones. Regarding cervical polyps we confirmed the absence of any correlation with EP and E (Table 4). Cervical polyps prevalence among controls and women with $\mathrm{EP}$ was $18 \%$ and $16 \%$ respectively. None of endometriosis patients, with or without EP, had cervical polyps.

\section{Conclusions}

The precise pathogenesis is still unclear both for endometriosis and endometrial polyps. However the most widely accepted commons characteristic is hormonal, namely unbalanced estrogenic milieu. Even though several pathogenetic mechanisms have been reported (Table 5), estrogens represent the common link. But is this link effective to justify and find out higher EP prevalence among endometriosis patients and inversely? Many Authors reported a strong association between E and EP [1] [4] [6] [11] [12] [13]. Moreover, Zheng indicated that stage 2 - 4 E patients have a significantly higher risk of EP [6].

Otherwhise Zhang [14] reported that the prevalence of endometrial polyps was significantly higher in the endometriosis group than in the control group $(\mathrm{P}<$ $0.001)$ but not significantly different between stages of endometriosis $(P=0.580)$. Upon pathological diagnosis $66.5 \%$ of endometrial polyps were combined with simple hyperplasia [14]. 
Table 1. Results from multicentric study upon hysteroscopic findings and presence/absence of endometriosis.

\begin{tabular}{lccc}
\hline & ENDOMETRIOSIS & ENDOMETRIOSIS & \\
& PRESENT & ABSENT & $\mathrm{P}<$ \\
& $\mathrm{N}=10$ & $\mathrm{~N}=275$ & \\
\hline ENDOMETRIAL POLYP PRESENT & $\mathbf{3 ( 3 0 \% )}$ & $143(52 \%)$ & $\mathrm{ns}$ \\
\hline
\end{tabular}

Table 2. Data from multicentric study. Patients are divided into 4 groups.

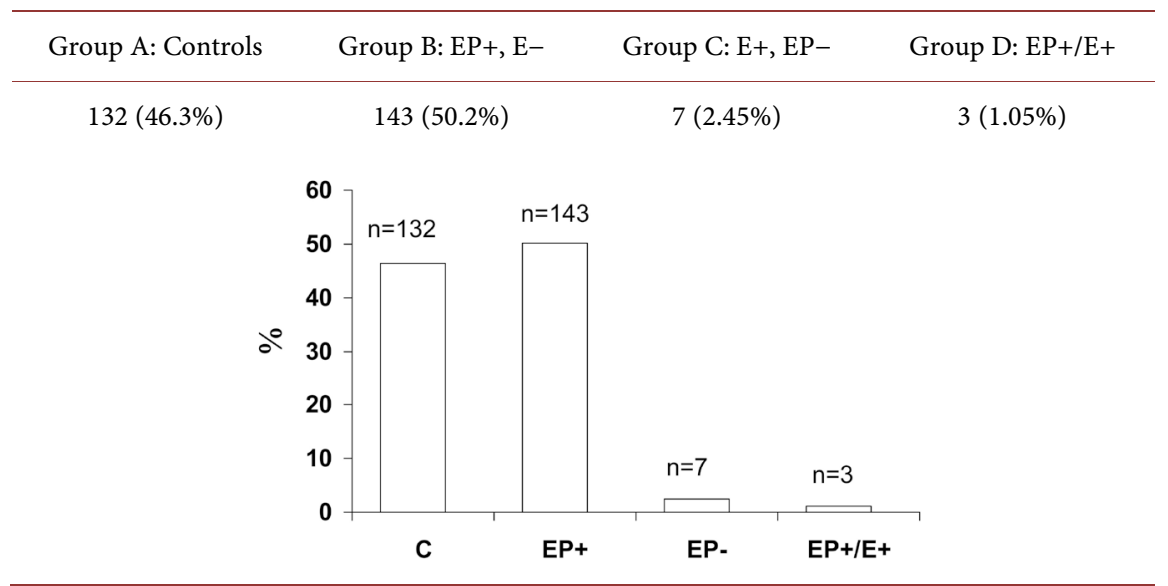

Legends: $\mathrm{E}=$ endometriosis; $\mathrm{EP}=$ endometrial polyp; +: present; -: absent.

Table 3. demographic and clinical characteristics of the participants.

\begin{tabular}{ccccc}
\hline & $\begin{array}{c}\text { Group A } \\
(\text { EP-/E- })\end{array}$ & $\begin{array}{c}\text { Group B } \\
(\text { EP+/E) }\end{array}$ & $\begin{array}{c}\text { Group C } \\
(\text { EP- and E+) }\end{array}$ & Group D (EP+/E+) \\
\hline Age (median) & 40 & 43 & 35 & 42 \\
BMI & $23.78(17-42)$ & $25(16-43)$ & $23.11(18.3-32)$ & 21.5 \\
infertility & $46 / 132(34 \%)$ & $24 / 141(16 \%)$ & $5 / 7$ & $2 / 3$ \\
Abortion/s & $14(10 \%)$ & $33(23 \%)$ & $0 / 7$ & $0 / 3$ \\
E/P therapy & $18 / 132$ & $34 / 141$ & $1 / 3$ & $6 / 7$ \\
Food & Omnivorous & Omnivorous & Omnivorous & Omnivorous \\
Site of residence & $70 \%$ urban & $80 \%$ urban & $100 \%$ urban & $100 \%$ urban \\
Cervical polyps & $24 / 132(18 \%)$ & $25 / 141(16 \%)$ & 0 & 0 \\
\hline
\end{tabular}

Legends: BMI reported median, the minimum value and the maxim value; E/P therapy = contraception; Food: omnivorous, vegan, vegetarian, gluten-free; Site of residence: urban, rural.

Table 4. Endometrial polyps, cervical polyps, endometriosis: our results.

\begin{tabular}{|c|c|c|c|c|c|}
\hline & $\begin{array}{l}\text { Endometriosis } \\
\qquad \mathrm{N}=7\end{array}$ & $\begin{array}{l}\text { Endometrial } \\
\text { polyps } \\
\mathrm{N}=143\end{array}$ & $\begin{array}{l}\text { Endometriosis + endometrial } \\
\text { polyps } \\
\mathrm{N}=3\end{array}$ & $\begin{array}{l}\text { Controls } \\
\mathrm{N}=132\end{array}$ & $\mathrm{P}<$ \\
\hline $\begin{array}{l}\text { Cervical } \\
\text { polyp } \\
\text { Present }\end{array}$ & 0 & $25(18 \%)$ & 0 & $24(16 \%)$ & ns \\
\hline
\end{tabular}


Table 5. Endometrial Polyps and Endometriosis: hypothesis of common aetiology and pathogenesis.

\begin{tabular}{|c|c|c|}
\hline Aetiology \& pathogenesis & Author & Year \\
\hline Eutopic and ectopic Endometrial overgrowth & Wang & \\
\hline 个estrogen receptors and haromatase & Noble & 1996 \\
\hline Testrogen receptors and haromatase & Maia & 2006 \\
\hline $\begin{array}{l}\text { Tendometrial proliferation, } \\
\text { endometrial apoptosis }\end{array}$ & Dmowski & 2001 \\
\hline $\begin{array}{l}\text { Tendometrial proliferation, } \\
\boldsymbol{V}_{\text {endometrial apoptosis }}\end{array}$ & Park & 2009 \\
\hline TVEGF, metalloproteinases $1,2,9$, angiogenesis factor $1-2$ & Machado & 2010 \\
\hline TVEGF, metalloproteinases $1,2,9$, angiogenesis factor $1-2$ & Cosin & 2010 \\
\hline 个progesterone receptor & Sant' Ana & 2004 \\
\hline Aprogesterone receptor & Lopez & 2007 \\
\hline Amast cells & Al Jefout & 2009 \\
\hline Tmast cells & El Hamarneh & 2013 \\
\hline Unopposed estrogenic milieu & MacBean & 1996 \\
\hline Unopposed estrogenic milieau & Hassa & 2012 \\
\hline
\end{tabular}

EP prevalence among the population we analyzed is quite high, $51.2 \%$. It probably depends on the selected population, at risk for endouterine abnormalities. On the other hand endometriosis prevalence is very low in the population studied. Self reporting of endometriosis disease could obtain higher numbers but may represent another bias. Small numbers of group C e D may weaken our study.

The absence of association between E and EP found in this study could be explained by Indraccolo's pathogenetic theory [15]. The onsetting of endometrial polyps may occur through estrogen-related and non-estrogen related ways. If this hypothesis would be confirmed, different data in terms of correlation between endometrial polyps and endometriosis would be explained.

We investigated about coexistence of endometrial and cervical polyps in cases and control groups (groups A and B). Cervical polyps's prevalence was not different among women with and without endometrial polyps, $15 \%$ and $18 \%$ respectively (Table 3). Dreisler et al. [7] reported samely absence of any correlation between endometrial and cervical polyps.

To the best of our knowledge, this is the first time that none correlation between $\mathrm{E}$ and EP is reported. Further research is needed, for understanding if there is a pathogenetic link between endometriosis and endometrial polyps. The results may be of great usefulness for infertile patients.

\section{Conflicts of Interest}

The authors declare no conflicts of interest regarding the publication of this paper. 


\section{References}

[1] MacBean, J., Gibson, M. and Brumsted, J.R. (1996) The Association of Intrauterine Filling Defects on Hysterosalpingogram with Endoetriosis. Fertility and Sterility, 66, 522-526. https://doi.org/10.1016/S0015-0282(16)58562-8

[2] Nijkang, N.P., Anderson, L., Markham, R. and Manconi, F. (2019) Endometrial Polyps: Pathogenesis, Sequelae and Treatment. SAGE Open Medicine, 7, 1-12. https://doi.org/10.1177/2050312119848247

[3] Hassa, H., Korkmazer, E., Tokgos, V.Y. and Oge, T. (2012) Independent Risk Factors for Endometrial Polyps: Diabetes, Hypertension and Obesity. Asian Pacific Journal of Reproduction, 1, 312-314. https://doi.org/10.1016/S2305-0500(13)60099-8

[4] Wang, N., Zhang, Y. and Liu, B. (2016) Demographic and Clinical Features of Endometrial Polyps in Patients with Endometriosis. BioMed Research International, 2016, Article ID: 1460793. https://doi.org/10.1155/2016/1460793

[5] Ghao, M., Allebeck, P., Mishra, D.G. and Koupil, I. (2019) Developmental Origins of Endometriosis: A Swedish Cohort Study. Journal of Epidemiology and Community Health, 73, 353-359.

[6] Zheng, Q.M., Mao, H.L., Zhao, Y.J., Wei, X. and Liu, P.S. (2015) Risk of Endometrial Polyps in Women with Endometriosis: A Meta-Analysis. Reproductive Biology and Endocrinology, 13, Article No. 103. https://doi.org/10.1186/s12958-015-0092-2

[7] Dreisler, E., Stampe Sorensen, S. and Lose, G. (2009) Endometrial Polyps and Associated Factors in Danish Women Aged 36-74 Years. American Journal of Obstetrics \& Gynecology, 200, 147.E1-147.E6. https://doi.org/10.1016/j.ajog.2008.08.065

[8] Check, J.H., Bostick-Smith, C.A., Choe, J.K., et al. (2011) Matched Controlled Study to Evaluate the Effect of Endometrial Polyps on Pregnancy and Implantation Rates Following in Vitro Fertilization-Embryo Transfer (IVF-ET). Clinical and Experimental Obstetrics and Gynecology, 38, 206-208.

[9] Scleedoorn, M.J., Nelen, W.L.D.M., Dunselman, G.A.J. and Vermeulen, N. (2016) Selection of Key Recommendations for the Management of Women with Endometriosis by an International Panel of Patients and Professionals. Human Reproduction, 31, 1208-1218. https://doi.org/10.1093/humrep/dew078

[10] Kitakawi, J., Kado, N., Ishihara, H., Koshiba, H., Kitaoka, Y. and Honjo, H. (2002) Endometriosis: The Pathophysiology as an Estrogen Dependent Disease. The Journal of Steroid Biochemistry and Molecular Biology, 83, 149-55. https://doi.org/10.1016/S0960-0760(02)00260-1

[11] Park, J.S., Lee, J.H., Kim, M., Chang, H.J., Hwang, K.J. and Chang, K.H. (2009) Endometrium from Women with Endometriosis Shows Increased Proliferation Activity. Fertility \& Sterility, 92, 1246-1249. https://doi.org/10.1016/j.fertnstert.2009.04.025

[12] El Fattah, E.A.A. (2017) Uterine Cavity Abnormalities in Patients with Endometriosis in Alexandria: A Diagnostic Test Accuracy Study. Obstetrics and Gynecology International, 2017, Article ID: 5869028. https://doi.org/10.1155/2017/5869028

[13] Kim, M.R., Kim, Y.A., Jo, M.Y., Hwang, K.J. and Ryu, H.S. (2003) High Frequency of Endometrial Polyps in Endometriosis. The Journal of the American Association of Gynecologic Laparoscopists, 10, 46-48. https://doi.org/10.1016/S1074-3804(05)60233-2

[14] Zhang, Y.N., Zhang, Y.S., Yu, Q., Guo, Z.Z., Ma, J.L. and Yan, L. (2018) Higher Prevalence of Endometrial Polyps in Infertile Patients with Endometriosis. Gynecologic and Obstetric Investigation, 83, 558-563. https://doi.org/10.1159/000487946 
[15] Indraccolo, U., Di Iorio, R., Matteo, M., Corona, G., Greco, P. and Indraccolo, S.R. (2013) The Pathogenesis of Endometrial Polyps: A Systematic Semi-Quantitative Review. European Journal of Gynaecological Oncology, 34, 5-22. 